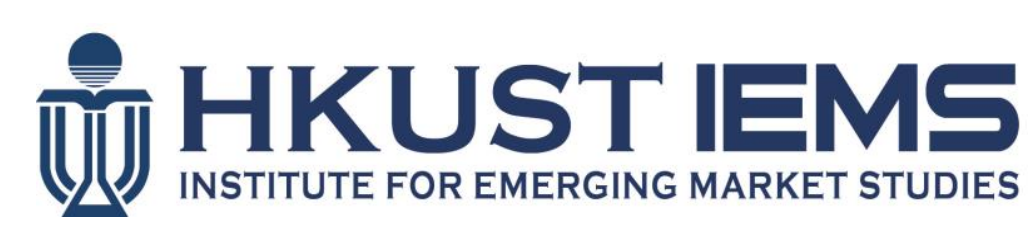

\title{
Growth, Pollution, and Life Expectancy: China from 1991-2012
}

\author{
Avraham EBENSTEIN, Maoyong FAN, Michael GREENSTONE, \\ Guojun HE, Peng YIN, Maigeng ZHOU
}

HKUST IEMS Working Paper No. 2015-10

February 2015

\begin{abstract}
HKUST IEMS working papers are distributed for discussion and comment purposes. The views expressed in these papers are those of the authors and do not necessarily represent the views of HKUST IEMS.
\end{abstract}

More HKUST IEMS working papers are available at: http://iems.ust.hk/WP 


\title{
Growth, Pollution, and Life Expectancy: China from 1991-2012
}

Avraham EBENSTEIN, Maoyong FAN, Michael GREENSTONE, Guojun HE, Peng YIN, Maigeng ZHOU

HKUST IEMS Working Paper No. 2015-10

February 2015

\begin{abstract}
This paper examines the relationship between income, pollution, and mortality in China from 1991-2012. Using first-difference models, we document a robust positive association between city-level GDP and life expectancy. We also find a negative association between city-level particulate air pollution exposure and life expectancy that is driven by elevated cardiorespiratory mortality rates. The results suggest that while China's unprecedented economic growth over the last two decades is associated with health improvements, pollution has served as a countervailing force.
\end{abstract}

\section{Author's contact information}

Avraham Ebenstein

Department of Economics, Hebrew University of Jerusalem, Mount Scopus, Israel

Maoyong Fan

Department of Economics, Ball State University, Muncie IN 47304, USA

Michael Greeenstone

Department of Economics, University of Chicago, Chicago IL 60637, USA and National Bureau of Economic Research, Cambridge MA 02138, USA

Guojun He

Division of Social Science, Division of Environment, and Department of Economics, The Hong Kong University of Science and Technology, Hong Kong, China

Peng Yin

National Center for Chronic and Non-communicable Disease Control and Prevention, Chinese Center for Disease Control and Prevention, Beijing, China

Maigeng Zhou

National Center for Chronic and Non-communicable Disease Control and Prevention, Chinese Center for Disease Control and Prevention, Beijing, China 


\title{
Growth, Pollution, and Life Expectancy: China from 1991-2012
}

\author{
Avraham Ebenstein, ${ }^{1}$ Maoyong Fan, ${ }^{2}$ Michael Greenstone, ${ }^{3}$ Guojun $\mathrm{He}^{4}$, Peng Yin ${ }^{5}$, Maigeng \\ Zhou $^{6}$
}

February 2015

\begin{abstract}
This paper examines the relationship between income, pollution, and mortality in China from 1991-2012. Using first-difference models, we document a robust positive association between city-level GDP and life expectancy. We also find a negative association between citylevel particulate air pollution exposure and life expectancy that is driven by elevated cardiorespiratory mortality rates. The results suggest that while China's unprecedented economic growth over the last two decades is associated with health improvements, pollution has served as a countervailing force.
\end{abstract}

Keywords: Growth, Pollution, Life Expectancy, China

JEL Classifications: Q13, P28, Q28, Q53

Acknowledgement: This study is supported by the China National Science and Technology Pillar Program 2013 (2013BAI04B02) from the Ministry of Science and Technology. We would also like to thank Walker Hanlon and Avi Simhon for very helpful comments.

\footnotetext{
1 Department of Economics, Hebrew University of Jerusalem, Mount Scopus, Israel

2 Department of Economics, Ball State University, Muncie IN 47304, USA

3 Department of Economics, University of Chicago, Chicago IL 60637, USA and National Bureau of Economic Research, Cambridge MA 02138, USA

4 Division of Social Science, Division of Environment, and Department of Economics, The Hong Kong University of Science and Technology, Hong Kong, China

${ }^{5}$ National Center for Chronic and Non-communicable Disease Control and Prevention, Chinese Center for Disease Control and Prevention, Beijing, China

${ }^{6}$ National Center for Chronic and Non-communicable Disease Control and Prevention, Chinese Center for Disease Control and Prevention, Beijing, China
} 
In the past two decades, China has experienced economic growth without historical precedent, with average income rising from $\$ 894$ per capita to $\$ 9,087$ (PPP). However, this incredible surge in income has not been matched by comparable health gains; life expectancy at birth increased by 5.4 years, a modest gain relative to neighboring countries such as Taiwan or South Korea (World Bank 2012). Furthermore, much of the improvement in Chinese life expectancy came from reductions in infant and child mortality which were "low hanging fruits", as China pulled millions of its citizens out of abject poverty and instituted basic improvements in sanitation and public health. In contrast, the gains in adult health outcomes have been considerably smaller, in spite of the ten-fold increase in average income. Adult mortality fell faster in Taiwan, South Korea, and even Japan during this period - all countries with economic growth less than half as robust as China's. This puzzling trend has begun to attract considerable attention (Yang et al. 2013) and begs an obvious question: why has China failed to enjoy a larger improvement in health amidst such astonishing economic growth?

One candidate explanation for China's modest growth in life expectancy is the country’s severe problems with air pollution. Since pollution is a byproduct of economic development, it may be that the benefits of greater income are offset by the cost of pollution exposure. This possibility has long been raised by those criticizing the emphasis on economic development above other priorities in low income countries. However, microeconometric evidence in favor of this hypothesis is scarce, possibly due to data limitations. Detailed cause of death data in developing countries are often unavailable, or available only at a national level. Similarly, local measures of economic growth are often unavailable or of low quality. As such, an accurate assessment of the benefits and costs of economic growth on pollution and mortality is often infeasible.

This paper examines the changes in Chinese mortality patterns using the most 
comprehensive data file ever compiled on health, pollution, and income in China. Importantly, these data cover the period 1991-2012, when China experienced its unprecedented economic boom. The analysis is conducted using detailed mortality data taken from China's Disease Surveillance Points System (DSPS), a mortality-monitoring system covering a nationally representative sample of Chinese cities and counties. These data are linked to air pollution data for 1980-2012 taken from physical copies of China's Environmental Yearbooks and electronic files provided by China's National Environmental Protection Agency. ${ }^{1}$ Lastly, we assign to each DSPS location a measure of local per capita GDP, facilitating an analysis of both the role of pollution and income growth in affecting health.

We present two analyses that suggest that China's air pollution is associated with its modest improvement in health outcomes. First, we document in the time series that causes of death which are presumably affected by pollution have declined much more slowly than other causes of death. In particular, heart disease, stroke, and lung cancer have remained at similar levels through the 1990s and 2010s, and these cardiorespiratory illnesses now comprise a much larger share of Chinese mortality. In contrast, mortality rates from non-cardiorespiratory illnesses, such as communicable diseases, have declined much more rapidly over the same period. Communicable disease mortality rates are very likely to be responsive hospital construction and public health initiatives, but less sensitive to pollution. As such, the cause-specific mortality trends suggest that China's income growth has improved health outcomes, but failed to do so for pollution-sensitive causes of death.

Second, we examine the association between health outcomes, income, and pollution

\footnotetext{
${ }^{1}$ In light of the lack of systematic data sources from China during this period, the pollution data represents a serious research challenge, and this paper makes significant though incomplete progress at generating a reliable archive of pollution data for China between 1980 and 2013.
} 
across regions of China. In cross-sectional models, we find that that income growth is associated with gains in life expectancy that are driven by declines in non-cardiorespiratory mortality rates. High pollution exposure is associated with declines in life expectancy, but this effect would not be judged statistically significant by conventional criteria. There is, however, a statistically significant relationship between pollution exposure and higher rates of cardiorespiratory mortality. We also estimate first-difference models where we examine changes across DSPS locations in mortality patterns between the beginning and end of our sample period, 1991-1993 and 2010-2012. We find that declines in particulate air pollution are associated with increases in average life expectancy and lower rates of cardiorespiratory mortality. The results suggest that air pollution may in fact be an important factor in explaining China's modest growth in life expectancy during a period of rapid economic development. However, these associational findings need to be probed further with quasi-experimental research designs that isolate plausibly exogenous variation in pollution (Dominici et. al. 2014).

\section{Economic Development and Pollution}

The health consequences of pollution in developing countries are difficult to isolate because income growth often occurs simultaneous to increases in pollution (and indeed may be a function of pollution), making it difficult to isolate the causal effect of pollution. More formally, consider a simple specification where life expectancy $(\mathrm{L})$ is a function of income $I$ and pollution $P$ and but income is a function of pollution:

$$
\begin{gathered}
L=H(I(P), P) \\
\frac{d L}{d P}=\frac{\partial H(I, P)}{\partial P}+\frac{\partial H(I, P)}{\partial I} \frac{\partial I}{\partial P}
\end{gathered}
$$

In this set-up, a regression of life expectancy on pollution confounds the positive effects of income 
growth with the potentially harmful consequences of pollution. Rather, it represents the net effect of pollution on health through the direct effect on life expectancy and an indirect effect through pollution's impact on income. Since some policy options involve changes in pollution that do not affect local incomes, it is critical to obtain the partial derivative of life expectancy with respect to pollution, rather than the total derivative. The next section outlines the data sources that we have amassed to infer this relationship using data from China over the last two decades.

\section{Data Sources and Descriptive Statistics}

Our analysis is executed on a merged sample of health, pollution, and income data between 1991 and 2012 that we believe is the most comprehensive data file ever compiled on health, pollution, and income in China. The mortality data are taken from the DSPS, a nationally representative sample with coverage of 145 locations between 1991 and 2000 and 161 locations between 2004 and 2012. The pollution data contain measures of Total Suspended Particulates (TSP), Particulate Matter (PM10), Sulphur Dioxide ( $\left.\mathrm{SO}_{2}\right)$, Nitrogen Oxides $\left(\mathrm{NO}_{\mathrm{x}}\right)$, and Nitrogen Dioxide $\left(\mathrm{NO}_{2}\right)^{2}$ The pollution data, it should be noted, are not systematically collected and digitized by Chinese authorities. As a result, one challenging aspect of this project is the collection of these data, the reconciliation of the data across multiple sources, and proper assignment of pollution exposure to the population at each DSPS location. ${ }^{3}$ Gross Domestic Product per capita is calculated for each DSPS location using income and population data from the Provincial and City Statistical

\footnotetext{
2 The measures of TSP and $\mathrm{NO}_{\mathrm{x}}$ are converted to $\mathrm{PM}_{10}$ and $\mathrm{NO}_{2}$ and are not shown. See details in the data appendix for the conversion factors.

${ }^{3}$ Assigning pollution accurately to DSPS locations has several challenging aspects. First, China's Environmental Yearbooks have incomplete readings for some of the stations, requiring us to interpolate missing data. Second, in limited instances, the data reported by the World Bank are not consistent with the reported reading in the Environmental Yearbooks. Third, we are forced in certain circumstances to choose between assigning pollution from a station which is closer to the DSPS location versus a station with more complete data. While in this project we follow the method outlined by Chen et al. (2013), in future work we plan to explore the sensitivity of our results to alternative decisions.
} 
Yearbooks. Lastly, the DSPS locations are merged with demographic information from the 1990 and 2010 census to obtain county-level information on average education, share of minority, and share with urban hukou (household registration).

The sample means are reported in Table 1 that compares China in 1991, 2000, and 2012, before, during and after its explosive economic growth. The summary statistics are reported for the subsample of DSPS locations within 150 kilometers of a pollution monitoring station; 36 DSPS locations for 1991-2000, and 154 DSPS locations in 2012 which we later use in our regressions. Several noteworthy patterns are immediately evident. First, life expectancy increased by 6.4 years between 1991 and 2012, raising average longevity from 69.3 to 75.7 years. However, much of the gain was from under-5 mortality, as life expectancy at age 5 remained at only 71.4 years, which is 4.3 years higher than two decades prior. The explanation for this comparatively modest improvement is found in the breakdown of cause-specific death rates, where we find striking differences between cardiorespiratory diseases versus the rest of causes of death. Noncardiorespiratory diseases, which include most communicable diseases and causes of death relevant to infants and young children, dropped dramatically from 432 to 221 deaths per 100,000. This is consistent with our understanding that China's rapid economic growth has enabled it to implement widespread improvements in public health and sanitation, thereby reducing mortality from diseases affecting the young. However, the results are more sobering for cardiorespiratory diseases: mortality from heart diseases, stroke, and lung cancer remained virtually unchanged during the period. ${ }^{4}$ These diseases are known to be sensitive to air pollution, as documented by a

\footnotetext{
4 The only cardiorespiratory cause that declined substantially during the period was "Respiratory diseases", mainly Chronic Obstructive Pulmonary Disease (COPD). One interpretation of the decline in respiratory diseases like COPD after 2000 is that the implementation of several national health insurances facilitated dealing with these respiratory diseases through health care access improvements, and this would compensate for any rise in these diseases because of pollution.
} 
rich medical literature (see Chen et. al 2013 for references). The results suggest that pollutionrelated diseases have continued to have high mortality rates in China, in spite of robust economic growth that appears to have facilitated substantial declines in other causes of death.

In the second panel, we report trends in the economic and demographic features of the DSPS locations. The results highlight China's rapid income growth, in which average per capita GDP rose by a factor of 10 at the DSPS locations, from an average of 4,317 yuan ( $\$ 900)$ to 40,151 $(\sim 6,360)$ in real terms. ${ }^{5}$ This trend in income is matched by a similarly impressive increase in average education, rising from 6.5 to 9.4 average years of completed schooling. The share of ethnic minorities remains similar at each DSPS location, but the proportion with urban hukou (household registration) rises in our data from 0.20 to 0.35 , reflecting greater urbanization in China.

The third panel reports trends in air pollution by the various pollutants monitored in China. Since China's monitoring system has not consistently monitored $\mathrm{PM}_{10}$ for the entire period, we impute $\mathrm{PM}_{10}$ from TSP for the station when necessary, using the assumption that $\mathrm{PM}_{10}$ represents 37.5\% of Total Suspended Particulates (TSP), which is the observed proportion in instances where both measures were collected. As shown in the table, the data reveal a striking decline for two of the air pollutants in the previous two decades. For example, particulate matter ( $\left.\mathrm{PM}_{10}\right)$ declines from 111.3 to 80.1 micrograms per cubic meter $\left(\mu \mathrm{g} / \mathrm{m}^{3}\right)$ in the two decades; this decrease of 33.3 $\mu \mathrm{g} / \mathrm{m}^{3}$ is more than the absolute level of pollution in many countries. ${ }^{6}$ As a point of reference, this decline is almost twice the average PM10 level in the United States of $18.0 \mu \mathrm{g} / \mathrm{m}^{3}$ (World Bank 2009). A similarly impressive decrease in sulfur dioxide $\left(\mathrm{SO}_{2}\right)$ levels occurred, from 82.1 to 34.9 $\mu \mathrm{g} / \mathrm{m}^{3}$. The only pollutants that did not register a decrease is nitrous dioxide $\left(\mathrm{NO}_{2}\right)$, which is

\footnotetext{
${ }^{5}$ We use 1:4.78 and 1:6.3 to convert RMB to USD in 1990 and 2012. All yuan figures are adjusted for the Chinese CPI and reported in 2010 yuan.

${ }^{6}$ Since PM10 was not collected in the 1990s, this calculation is using an imputation that PM10 is $37 \%$ of TSP. Details of the imputation are available in the online data appendix.
} 
generated primarily by automobiles exhaust, and would be unlikely to decrease amid such a rapid increase in the Chinese domestic auto market during the period.

There are some important and subtle issues related to the relationship between adult mortality and air pollution. Previous research has documented a relationship between short-run mortality rates and short-run pollution measures (Samet et al. 2000), but whether this variation produces substantial changes in life expectancy is unclear. In the subsequent analysis, we focus on long-run pollution exposure. Our health outcomes are averaged across years to create a single observed life expectancy and mortality rate at each DSP location during each sample period. We define long-run pollution exposure as the average pollution reading assigned to the DSP location in all years prior to the observed year, and including the year itself. As a result, while the declines in annual pollution in Table 2 are substantial, their influence on lifetime exposure is more muted when using our long-run measures. For example, the population at a DSPS location in 1991 and in 2012 will both have been exposed to the 1980s pollution at the location. Therefore, both the level and timing of a pollution decline will factor into our estimated pollution exposure at any given DSPS location.

\section{Assessing the Relationship between Health, Pollution, and Income}

Table 2 presents the results from regressing a series of health outcomes against exposure to particulate matter (TSP and PM10), and per capita GDP. Specifically, we estimate 3 sets of regressions displayed in panels A, B, and C: cross-sectional with 1991-2000, cross-sectional with 2004-2012, and a first-difference specification where we regress changes in the outcome variables on changes in pollution exposure and changes in per capita GDP between the two periods. Our outcome variables (displayed in the column headers) are life expectancy at birth, life expectancy at age 5 , age-adjusted death rate from cardiorespiratory mortality, and age-adjusted death rate from 
all other causes of death.

In Panel A, we focus on 1991-2000. The results reflect a strong positive relationship between GDP and life expectancy, driven primarily by its negative impact on the noncardiorespiratory rate. A doubling of income is predicted to have a 3.5 year gain in life expectancy and reduce non-cardiorespiratory mortality by 121 deaths per hundred thousand, or roughly $28 \%$ $(=121 / 431)$ from its level in 1991. These findings fit the conventional wisdom; as China began to pull itself from poverty, the first gains were from reductions in infant mortality and childhood diseases, yielding large gains in these causes of death. Notably, the results fail to find a statistically significant relationship between income and life expectancy at age 5.

The table also reveals a significant positive association between TSP exposure and the death rate from cardiorespiratory mortality. The estimates suggest that an additional $100 \mu \mathrm{g} / \mathrm{m}^{3}$ of TSP raise the cardiorespiratory mortality rate by 25 per hundred thousand, an increase of roughly $5.8 \%$ (25/432) from its level in 1991. Although TSP is negatively correlated with both life expectancy measures, these relationships would not be judged to be statistically significant.

The results in Panel B are very similar to those reported in Panel A. Here, the sample is composed of DSPS locations observed between 2004 and 2012 and we use direct measurement of $\mathrm{PM}_{10}$. The results are similar in that income growth is positively associated with life expectancy at birth, though with a lower estimated semi-elasticity. Income is again associated with stronger declines in non-cardiorespiratory mortality. Finally, particulate matter is positively correlated with cardiorespiratory mortality, with a 100 microgram increase in $\mathrm{PM}_{10}$ resulting in an increase in the mortality rate from these causes by 50 per hundred thousand, an increase of over 11\% (50/463) relative to the 2000 mortality level from these diseases.

Panel C presents the results of a first-difference specification that examines the relationship 
between changes in health and changes in income and pollution over time. ${ }^{7}$ In this exercise, each location is assigned its average values during 1991-1993, its average values during 2010-2012, and the difference between these two averages. This enables us to compare the same DSPS location after two decades of radical change in China and relies on an alternative source of variation than is utilized in the cross-sectional results in Panels A and B. Specifically, the first-differencing purges the estimates of the influence of all time invariant determinants of the health outcomes, such as differences in diet or smoking rates. ${ }^{8}$ Of course, the estimates of the effects of GDP and pollution may still be confounded by time-varying DSPS-level factors and the role of measurement error, which may produce greater attenuation bias than in the cross-sectional approach. However, the results suggest that economic growth is a key predictor of growth in life expectancy: a doubling of economic growth is associated with an additional 2.4 years of life expectancy. The first difference results suggest that GDP growth during these two decades is also associated with important declines in both cardiorespiratory and non-cardiorespiratory diseases. Interestingly, the point estimates are comparable to those from the cross-sectional equations. Overall, the per capita income results suggest that income is protective of health and a doubling is associated with a 2-3 year increase in life expectancy at birth. Since income increased by 10 fold in this period in real terms and total life expectancy increased by 6.4 years, it appears that there was a countervailing force that reduced life expectancy.

The results in Panel C also highlight the long-term consequences of pollution exposure: we

\footnotetext{
7 The first-difference approach has been used in the U.S. context, and found evidence of an important relationship between exposure to fine particulate matter and health (Pope et al. 2009).

${ }^{8}$ Smoking and diet are two critical predictors of cardiorespiratory diseases. Ideally, we would have measures over time so that we could accurately capture changes in behavior that affect health. Unfortunately, we cannot observe changes in diet or smoking in our data, and so using a first-difference strategy effectively purges the results of regional variation in these behaviors, but does not remove bias from changes in these behaviors that are correlated with either GDP growth or pollution.
} 
estimate that a $100 \mu / \mathrm{m}^{3}$ increase in $\mathrm{PM}_{10}$ exposure is associated with a decline in life expectancy of 1.5 years at birth, a decline in life expectancy of 2.3 years at age 5, and an increase in the cardiorespiratory mortality rate of 79 per hundred thousand. These results are suggestive evidence that Chinese counties with greater pollution increases (or smaller pollution decreases) are experiencing slower life expectancy increases and have experienced higher cardiorespiratory mortality rates during adulthood. ${ }^{9}$ As a benchmark for what this effect implies, consider two cities which are roughly at the $25^{\text {th }}$ and $75^{\text {th }}$ percentiles of the distribution of $\mathrm{PM}_{10}$ changes in our sample: Wuhan and Qingdao. While Qingdao enjoyed a decline of $67.9 \mu / \mathrm{m}^{3}$ of $\mathrm{PM}_{10}$, the decline in Wuhan was only $19.2 \mu / \mathrm{m}^{3}$. Our estimates, if taken literally, imply that Wuhan's population would enjoy .75 $(48.7 * 1.55)$ years lower life expectancy at birth, and $1.11(48.7 * 2.27)$ years lower life expectancy at age 5 relative to the inhabitants in Qingdao as a result of their faster decline in pollution. This suggests that the magnitude of our estimates are sufficiently large that air pollution may be resulting in significant welfare losses among those exposed to China's highest $\mathrm{PM}_{10}$ concentrations.

\section{Discussion and Future Directions}

In the past 2 decades, while rapid economic development has led to a decline in China's mortality rate among infants and young children, the health gains have been more modest among adults. A candidate explanation for this trend is long-term exposure to air pollution, which raises the mortality rates from cardiorespiratory diseases. We have presented suggestive evidence that this is indeed the case. In light of these potentially large impacts on well-being, an urgent area for future research is to probe the validity of this paper's findings with quasi-experimental designs

\footnotetext{
9 The results across all three panels are robust to inclusion of our demographic control variables listed in Table 1: years of education, share of minority, and share with urban hukou. Results available from the authors upon request.
} 
where the source of variation in pollution is better understood (Dominici et al. 2013). ${ }^{10}$

${ }^{10}$ See Chen et. al (2013) and Rich et al. (2013) for recent examples of the application of quasi-experimental approaches to estimating the relationship between air pollution and human health in China. 


\section{Refere nces}

Almond, D., Greenstone, M., Chen, Y., \& Li, H. (2009). "Winter Heating or Clean Air? Unintended Impacts of China’s Huai River Policy". The American Economic Review: Papers and Proceedings, 99(2), 184-190.

Chen, Y., Ebenstein, A., Greenstone, M. \& Li, H. (2013). "Evidence on the Impact of Sustained Exposure to Air Pollution on Life Expectancy from China's Huai River Policy". Proceedings of the National Academy of Sciences USA 2013. August 6; 110(6):12936-41

Dominici, F., Greenstone, M. \& Sunstein, C. R. (2014). "Particulate Matter Matters". Science, 344(6181), 257-259.

Pope, C. A., Ezzati, M., \& Dockery, D. W. (2009). "Fine-Particulate Air Pollution and Life Expectancy in the United States". New England Journal of Medicine, 360(4), 376-386.

Rich, D. Q., Kipen, H. M., Huang, W., Wang, G., Wang, Y., Zhu, P., \& Ohman-Strickland, P. (2012). "Association Between Changes in Air Pollution Levels During the Beijing Olympics and Biomarkers of Inflammation and Thrombosis in Healthy Young Adults". JAMA, 307(19), 2068-2078.

Samet, Jonathan. Francesca Dominici, Frank C. Curriero, Ivan Coursac, and Scott L. Zeger. 2000. “Fine Particulate Air Pollution and Mortality in 20 U.S. Cities, 1987-1994”. New England Journal of Medicine 343:1742-1749.

World Bank. 2012. "World Development Indicators, 1990-2012", Retrieved from http://data.worldbank.org/country.

Yang, Gonghuan, Yu Wang, Yixin Zen, George Gao, et al. 2010 "Rapid Health Transition in China, 1990-2010: findings from the Global Burden of Disease Study”. The Lancet 381(9882):1987-2015. 
Table 1- Trends in Health, Income and Pollution in China, 1991-2012

\begin{tabular}{|c|c|c|c|}
\hline & 1991 & 2000 & 2012 \\
\hline \multicolumn{4}{|c|}{ Panel A: Life Expectancy and Cause-Specific Death Rates } \\
\hline Life Expectancy at Birth & $\begin{array}{l}69.3 \\
(6.6)\end{array}$ & $\begin{array}{l}71.5 \\
(5.6)\end{array}$ & $\begin{array}{l}75.7 \\
(3.5)\end{array}$ \\
\hline Life Expectancy at Age 5 & $\begin{array}{l}67.1 \\
(5.9)\end{array}$ & $\begin{array}{l}68.1 \\
(5.1)\end{array}$ & $\begin{array}{l}71.4 \\
(3.3)\end{array}$ \\
\hline All Cause Mortality (per 100,000) & $\begin{array}{c}863.4 \\
(305.4)\end{array}$ & $\begin{array}{c}821.2 \\
(341.2)\end{array}$ & $\begin{array}{c}531.7 \\
(135.7)\end{array}$ \\
\hline$\underline{\text { Cardirespiratory Diseases }}$ & $\begin{array}{c}432 \\
(214.8)\end{array}$ & $\begin{array}{c}463.4 \\
(236.6)\end{array}$ & $\begin{array}{c}310.3 \\
(100.1)\end{array}$ \\
\hline Heart Diseases & $\begin{array}{l}114.4 \\
(84.6)\end{array}$ & $\begin{array}{l}122.2 \\
(83.7)\end{array}$ & $\begin{array}{l}107.2 \\
(46.0)\end{array}$ \\
\hline Stroke & $\begin{array}{l}121.4 \\
(84.5)\end{array}$ & $\begin{array}{l}156.5 \\
(94.0)\end{array}$ & $\begin{array}{l}114.6 \\
(49.2)\end{array}$ \\
\hline Lung Cancer & $\begin{array}{c}23.2 \\
(18.2)\end{array}$ & $\begin{array}{c}31.3 \\
(20.7)\end{array}$ & $\begin{array}{c}34.4 \\
(12.3)\end{array}$ \\
\hline Respiratory Diseases & $\begin{array}{c}172.9 \\
(131.8)\end{array}$ & $\begin{array}{c}153.4 \\
(118.5)\end{array}$ & $\begin{array}{c}54.2 \\
(40.8)\end{array}$ \\
\hline Non-Cardiorespiratory Diseases & $\begin{array}{c}431.5 \\
(203.3)\end{array}$ & $\begin{array}{c}357.8 \\
(158.5)\end{array}$ & $\begin{array}{l}221.4 \\
(59.7)\end{array}$ \\
\hline Cancers other than Lung & $\begin{array}{l}108.3 \\
(62.7)\end{array}$ & $\begin{array}{l}118.9 \\
(68.1)\end{array}$ & $\begin{array}{c}94.3 \\
(30.0)\end{array}$ \\
\hline Injury & $\begin{array}{c}83.1 \\
(53.1)\end{array}$ & $\begin{array}{c}70.8 \\
(36.3)\end{array}$ & $\begin{array}{c}49.6 \\
(24.5)\end{array}$ \\
\hline All Other Causes & $\begin{array}{c}240.1 \\
(176.0)\end{array}$ & $\begin{array}{c}168.1 \\
(123.9)\end{array}$ & $\begin{array}{c}77.5 \\
(36.7)\end{array}$ \\
\hline \multicolumn{4}{|c|}{ Panel B: Income and Demographic Characteristics } \\
\hline GDP Per Capita (2010 yuan ) & $\begin{array}{c}4,317 \\
(2,167)\end{array}$ & $\begin{array}{c}9,546 \\
(5,320)\end{array}$ & $\begin{array}{c}40,151 \\
(16,052)\end{array}$ \\
\hline Educational level (years) & $\begin{array}{l}6.5 \\
(1.6)\end{array}$ & $\begin{array}{l}7.8 \\
(1.3)\end{array}$ & $\begin{array}{l}9.4 \\
(1.4)\end{array}$ \\
\hline Share Minority & $\begin{array}{l}0.10 \\
(0.24)\end{array}$ & $\begin{array}{l}0.09 \\
(0.21)\end{array}$ & $\begin{array}{l}0.09 \\
(0.21)\end{array}$ \\
\hline Share with Urban hukou & $\begin{array}{l}0.20 \\
(0.30)\end{array}$ & $\begin{array}{l}0.28 \\
(0.26)\end{array}$ & $\begin{array}{l}0.35 \\
(0.26)\end{array}$ \\
\hline \multicolumn{4}{|l|}{ Panel C: Pollution Measures } \\
\hline Particulate Matter ${ }^{1}\left(\mathrm{PM}_{10}, \mu \mathrm{g} / \mathrm{m}^{3}\right)$ & $\begin{array}{l}111.3 \\
(41.8)\end{array}$ & $\begin{array}{l}87.9 \\
(44.4)\end{array}$ & $\begin{array}{l}80.1 \\
(21.0)\end{array}$ \\
\hline Sulphur Dioxide $\left(\mathrm{SO}_{2}, \mu \mathrm{g} / \mathrm{m}^{3}\right)$ & $\begin{array}{l}82.1 \\
(67.2)\end{array}$ & $\begin{array}{l}47.9 \\
(39.2)\end{array}$ & $\begin{array}{l}34.9 \\
(12.4)\end{array}$ \\
\hline Nitrogen Dioxide ${ }^{2}\left(\mathrm{NO}_{2}, \mu \mathrm{g} / \mathrm{m}^{3}\right)$ & $\begin{array}{l}33.0 \\
(16.7)\end{array}$ & $\begin{array}{l}35.0 \\
(19.2)\end{array}$ & $\begin{array}{l}32.5 \\
(11.0)\end{array}$ \\
\hline
\end{tabular}

Notes: Author calculations using the Chinese Disease Surveillance Points Survey (19912012). Income data is taken from China's Statistical Yearbooks . Pollution measures are taken from China's Environmental Yearbooks (1981-2012). ${ }^{1}$ Particulate matter and ${ }^{2}$ Nitrous Oxide were not collected in 1991. Fine particulate matter is imputed in 1991 by assuming is a fixed proportion of Total Suspended Particulates. Nitrogen Dioxide is imputed in 1991 by assuming it is a fixed proportion of Nitrogen Oxides. 
Table 2- Estimating the Relationship Between Health, Income and Pollution

\begin{tabular}{|c|c|c|c|c|}
\hline & $\begin{array}{l}\text { Life } \\
\text { Expectancy } \\
\text { at Birth } \\
\text { (years) } \\
(1) \\
\end{array}$ & $\begin{array}{l}\text { Life } \\
\text { Expectancy } \\
\text { at Age } 5 \\
\text { (years) } \\
\text { (2) } \\
\end{array}$ & $\begin{array}{c}\text { Cardio- } \\
\text { respiratory } \\
\text { Mortality Rate } \\
\text { (per } 100,000 \text { ) } \\
(3) \\
\end{array}$ & $\begin{array}{c}\text { Non Cardio- } \\
\text { respiratory } \\
\text { Mortality Rate } \\
\text { (per } 100,000) \\
(4) \\
\end{array}$ \\
\hline \multicolumn{5}{|c|}{ Panel A: Cross-Sectional Models using DSP locations in 1991-2000 } \\
\hline Log of Per Capita GDP & $\begin{array}{c}3.525^{* * *} \\
(1.033)\end{array}$ & $\begin{array}{l}1.705^{*} \\
(0.963)\end{array}$ & $\begin{array}{l}-38.75 \\
(25.76)\end{array}$ & $\begin{array}{c}-121.4^{* * *} \\
(24.45)\end{array}$ \\
\hline TSP $\left(100 \mu \mathrm{g} / \mathrm{m}^{3}\right)$ & $\begin{array}{l}-0.147 \\
(0.270)\end{array}$ & $\begin{array}{c}-0.317 \\
(0.256)\end{array}$ & $\begin{array}{c}24.99 * * * \\
(9.137)\end{array}$ & $\begin{array}{l}-10.59 * \\
(5.884)\end{array}$ \\
\hline R Squared & 0.074 & 0.032 & 0.083 & 0.156 \\
\hline \multicolumn{5}{|c|}{ Panel B: Cross-Sectional Models using DSP locations in 2004-2012 } \\
\hline Log of Per Capita GDP & $\begin{array}{c}2.214^{* * *} \\
(0.559)\end{array}$ & $\begin{array}{c}1.514 * * * \\
(0.523)\end{array}$ & $\begin{array}{l}-31.09 * \\
(15.75)\end{array}$ & $\begin{array}{c}-51.36 * * * \\
(12.24)\end{array}$ \\
\hline $\mathrm{PM}_{10}\left(100 \mu \mathrm{g} / \mathrm{m}^{3}\right)$ & $\begin{array}{l}-0.705 \\
(0.535)\end{array}$ & $\begin{array}{l}-0.734 \\
(0.473)\end{array}$ & $\begin{array}{c}50.48 * * * \\
(13.25)\end{array}$ & $\begin{array}{l}-20.28 * \\
(10.78)\end{array}$ \\
\hline R Squared & 0.092 & 0.061 & 0.113 & 0.120 \\
\hline \multicolumn{5}{|c|}{ Panel C: First Differences comparing DSP locations in 1991-93 and 2010-12 } \\
\hline Log of Per Capita GDP & $\begin{array}{c}2.399 * * * \\
(0.569)\end{array}$ & $\begin{array}{c}1.281 * * \\
(0.563)\end{array}$ & $\begin{array}{c}-46.74 * * * \\
(14.52)\end{array}$ & $\begin{array}{c}-88.16^{* * *} \\
(13.13)\end{array}$ \\
\hline $\mathrm{PM}_{10}\left(100 \mu \mathrm{g} / \mathrm{m}^{3}\right)$ & $\begin{array}{l}-1.547 \\
(1.096)\end{array}$ & $\begin{array}{c}-2.272 * * \\
(1.051)\end{array}$ & $\begin{array}{l}78.59 * * \\
(37.42)\end{array}$ & $\begin{array}{c}45.60 \\
(51.06)\end{array}$ \\
\hline R Squared & 0.348 & 0.204 & 0.381 & 0.519 \\
\hline
\end{tabular}

Notes: The sample in Panel A is composed of 136 DSP locations, and 154 DSP locations in

Panel B. The sample in Panel C is restricted to locations observed both periods, which containts 84 DSP locations. In each set of regressions, the outcome variable represents collapsed measures of the health outcomes across the years in the listed period. The pollution measure is the average pollution reading assigned to the DSP location in all years prior to the observed year, and including the year itself. See the data appendix for details of the assigment rule. In Panels A and B, we regress health outcomes on levels of pollution and local income. In Panel C, we regress changes in health outcomes on changes in pollution and local GDP, comparing 1991-1993 to 2010-2012. Standard errors are reported below coefficients in parentheses, and are heteroskedastic-consistent. * significant at $10 \% * *$ significant at $5 \%$. ${ }^{* * *}$ significant at $1 \%$. 


\section{Online Data Appendix - Not for Publication}

\section{Mortality and Life Expectancy Data}

Our measure of mortality is taken from the Disease Surveillance Point System (DSPS) of China. For a selected surveillance point (either a county or a city-district), the DSPS collects data on all deaths in hospital or at home. To represent national population and mortality trends, the DSPS adopts a multi-stage cluster population probability sampling method. The main objectives of the DSPS are to: (1) identify the number of deaths related to each disease category and provide basic mortality information about the deceased for public health officials; and (2) provide feedback to evaluate the impacts of the public health interventions. The DSPS initially covered 71 counties and city-districts in 29 provinces; this was expanded to 145 counties and city-districts in 31 provinces in 1990. The DSPS was overhauled following the SARS outbreak in 2003 and 161 counties and city-districts were designated in the system from 2004 to the present. Currently, the DSPS covers more than 81.5 million people or roughly 6 percent of the Chinese population. Our data period ranges from 1991 through 2012. ${ }^{11}$ We have 102 DSPS monitor points that existed in the whole period and 84 with valid pollution measurements. It is worth noting, however, that the DSPS post-2004 defined as its coverage population the entire county's population, whereas that prior to 2000, each point covered roughly a third of the county's population.

Death rates at each DSPS location are calculated for 19 age groups: 0, 1, 2-5, 6-10, 11 $15 \ldots, 75-80,80-85$ and older than 85 . These age-specific rates are then used to create age-adjusted rates using the national age distribution for China in 2000. The age-adjusted rates are used to generate abridged life tables, which are in turn used to calculate life expectancy at each age using standard demographic techniques.

\section{Pollution Data}

Our pollution data are formed by combining several sources of Chinese air pollution, and is to our knowledge the most comprehensive data ever assembled for the period 1981-2012. These data were compiled through hand entry from Chinese language publications; most readings were taken from China’s Environmental Yearbooks 1990-2012 and China’s Environmental Quality Annual Reports 2001-2012, and verified against each other. In more

11 Due to the large scale transition of data collection system in early 2000s, the mortality data in 2001, 2002, and 2003 are poorly collected and the China’s CDC deems the data in those three years unusable. 
recent years, the Chinese EPA provided us electronic copies of the data sources, which we used to verify our readings taken from the hard-copy publications.

Our data contain measures of several pollutants. The main pollutant we focus on is particulate matter, since this is considered the most harmful form of air pollution. The Chinese monitoring system reported Total Suspended Particulates (TSP) between 1981 and 2004 for a collection of cities, but discontinued reporting TSP in 2005. For 2003-2012, we have data on $\mathrm{PM}_{10}$, particulate matter which is considered a more dangerous form of pollution. In our data, $\mathrm{SO}_{2}$ concentrations have been reported consistently during our sample period (1990-2012). Concentrations of NOx were reported for selected cities before 2001. Since 2001 all reporting is in terms of $\mathrm{NO}_{2}$. In order to facilitate analysis over our entire period, such as in the first difference specification, we impute PM10 from recorded TSP by assuming 37\% of TSP is PM10 (which is based on the average for periods in which both were recorded). Similarly, $\mathrm{NO}_{2}$ is assumed to be assumed to be $75 \% \mathrm{NO}_{\mathrm{x}}$.

The assignment of pollution to DSPS locations is equivalent to the manner described in Chen et al. (2013). In brief, we create a data set of pollution readings by monitoring station and year from China's Environmental Yearbooks. We then calculate the distance for each pair of monitoring stations and DSPS locations. The distance between each of these stations and our 204 DSPS locations yields a full matrix of calculated distances. Our measure of air pollution for a DSPS location in a year is calculated as the weighted average of air pollution at each station, with the weights determined by the inverse of the distance between the two points, provided the station is less than 150 kilometers from the DSPS location. When a station had no valid TSP or PM10 reading for a particular year, it was assigned a zero weight for that year and did not enter into the calculation. For DSPS locations within 25 kilometers of a monitoring station, we simply use the reading from the closest station instead of the distance-weighted measure. For DSPS locations not within 150 kilometers of a monitoring station, they are not assigned pollution and are dropped from the sample.

Finally, at each DSPS location, the air pollution exposure was measured as the average TSP reading in all previous years when data are available. The assignment rule is to use all available data for each location retrospectively, and use TSP/PM10 conversions when necessary. For example, the reading for a DSPS location in 1991 is the average of TSP readings from 19811990 at the location. For a DSPS location in 2010, the reading would be calculated using all 
$\mathrm{PM}_{10}$ readings between 2003 and 2009, and then using TSP*.37 for 2002 and earlier as our imputed measure of PM10. This creates a panel data set of year by DSPS location mortality readings with validated air pollution data averaged across all previous years.

\section{Income and Demographic Data}

We collected GDP and population data from China's statistical yearbooks for each DSPS location. For urban DSPS locations, the city-level GDP and population measures were taken from China’s City Statistical Yearbooks. For rural DSPS locations, county-level GDP were taken from China's County Statistical Yearbooks, and Provincial Statistical Yearbooks when necessary. Per capita GDP is calculated as GDP divided by end-year population. We then adjust for inflation using China’s national CPI (2010=100).

Our measure of GDP for 1990 and 2012 is generated using China's statistical records, which are comprehensive at the province-level but incomplete at the county or city level. In 2012, we are able to observe actual per capita GDP at the county level or city level for all but a few counties in Tibet. For these counties, we use province-level GDP per capita. In 1990, county-level GDP is not available. As such, we impute per capita GDP in 1990 using the 2000 GDP per capita, and deflating by the province growth in GDP between 1990 and 2000. 